\title{
Digital Economy and Anti-Corruption: New Digital Models
}

\author{
E.L. Sidorenko ${ }^{1, *}$, and A.A. Lykov ${ }^{1}$ \\ *Corresponding author: 12011979@list.ru. \\ ${ }^{1}$ MGIMO University, Moscow, Russia
}

\begin{abstract}
The authors of this paper consider promising areas of the corruption prevention using the latest digital technologies: Blockchain, Internet of Things, Artificial Intelligence and Big Data. The purpose of this research is the analysis of advantages of the digital economy development in terms of solving social problems and crime prevention. The authors also show functional digital models of the anti-corruption compliance are defined. In addition, the research results include the determination of some shortcomings of the proposed models associated with the imperfection of the current legislation.
\end{abstract}

Keywords: digital public administration; risk assessment; overview of the changes, digital transformation.

\section{Introduction}

Nowadays, the use of digital technologies for the corruption prevention is a new interdisciplinary point of application of forces of both lawyers and specialists in the field of the sophisticated technology. However, imprudent use of digitalization tools can have significant negative social and political consequences. In this regard, the theoretical development of this area is an important step towards the harmonization of law with the use of new digital tools.

\section{Problem Statement}

The active development of digital technologies in the framework of e-government and digital society programs poses a number of urgent tasks for researchers related to the search for the most effective directions of digitalization in terms of the optimal ratio of the effectiveness and cost of these reforms. In the last three years, three main priorities have been identified: the development of the financial system through the introduction of transparent and verifiable technologies; the improvement of the public administration system and crime prevention.

And if it is possible to calculate the effectiveness of the first two areas only after 3-5 years, the crime prevention using digital technologies shows its effectiveness during the first two years. Many works of both domestic $[1,2]$ and foreign authors [3, 4] are devoted to the use of digital technologies while committing crimes, as well as in the framework of their usage for the crime prevention. The researchers pay special attention to the assessment of theft of digital assets and legalization of crimes using cryptocurrency, but ignore another important problem - the prevention of corruption. Meanwhile, the transparency, accessibility and universality of digital technologies make them as convenient as possible for use in the detection and prevention of corruption.

According to the UNO development program, a 1\% increase in the e-government implementation index in 2016 leads to a $1.17 \%$ reduction in corruption $[5,6]$. According to the research of the Center for digital technologies and financial innovations of MGIMO, there is an inverse connection between the dynamics of the public sector digitalization and the corruption crime level: in 2018, in some regions of the country, with an increase in the volume of digitalization in the "state - man" sector by $5 \%$, the level of domestic corruption decreased by $3 \%$. Such dynamics is noted, in particular, in Moscow and the Republic of Tatarstan.

\section{Research Questions}

According to some experts [7], the introduction of new digital technologies itself leads to a decrease in crime [8] by reducing the information deficit, automating processes and limiting the margin of appreciation by state employees and intermediaries. For example, the introduction of an automated tax administration in Afghanistan has reduced the margin of appreciation by tax officials, with the result that the amount of collected taxes has increased from 250 million to 2 billion since 2004 [9].

In addition, the transparency of public administration provided by digital technologies makes it available for public supervision, which, on the one hand, reduces the level of public distrust in the government and makes the system of public services available, on the other hand, expands the possibility of expert support by establishing feedback with government agencies and allows to clarify official information.

But despite the obvious benefits of the digital technology to ensure the transparency of the public administration system and disclosure corruption offenses, there is no doubt the limited positive effect of this technology is largely 
determined by the underdeveloped digital infrastructure (lack of broadband Internet, lack of development of online services, digital illiteracy of the population, etc.).

But speaking about the undoubted advantages of digital technologies in preventing corruption, the field of research should include those negative consequences that can accompany the digitalization process. Among them are the following ones:

- weak personal data protection systems and vulnerability of databases for hacking using fundamentally new cyber attacks, facilitated access to the confidential information by database hacking [8];

- absence of an adopted system of responsibility measures for abuses with the new technologies usage;

- widespread dissemination of false information and lack of effective mechanisms to prevent it;

- excessive duplication of information in different databases because of the lack of direct channels between them for the exchange and verification of data, etc. (in this situation, there is a high risk of the information falsification about the corruption facts or overestimation of indicators by their uncontrolled duplication);

- lack of clear criteria for the technology evaluation (due to its novelty, the introduced technology does not have a clear value expression, which significantly increases the corruption risks in public procurement;

- low development of the digital ethics and culture of new technologies users (In Bosnia and Herzegovina, for example, several officials used an electronic registration system to issue fake identification documents [8]; at the same time, the regional public administration school has established numerous cases when civil servants used "e-government" tools for corruption: a Croatian police officer deleted data on traffic violations from the system for bribing wine and fried lamb; Croatian officials registered trucks as cars in the road toll system, the damage from this activity exceeded 2 million euros per year [10].

\section{Purpose of the Study}

The aim of the study is to analyze the current situation in the context of the considered issues and identify the main functional models of the corruption prevention using digital technologies. The authors also try to assess the effectiveness of these models on the basis of the current legislation.

\section{Research Methods}

The main research method is analysis. The analysis is based on sociological methods of processing statistical information about the state and dynamics of corruption, as well as a modeling method that allowed to build digital models of the corruption prevention, study and assess the effectiveness, as well as propose ways for their optimization.

\section{Findings}

Taking into account the previously identified risks, we considered the most effective solutions for the corruption prevention with the use of new digital technologies. Depending on the functionality of technologies, digital models of the corruption prevention can be divided into the following groups:

- ensuring the work transparency of state bodies and the formation of new digital platforms for collecting information about the commission of corruption crimes (transparency model);

- creation of feedback platforms between government agencies and consumers of public services for the rapid receipt of data on abuse of officials (feedback model);

- digital protection for the electronic document flow and public information (open document flow model);

- assessment of possible corruption risks and digital definition of conflict of interest (digital compliance model);

- reduction of the margin of appreciation by individuals potentially exposed to corruption (model for automated decision-making process);

- exclusion of a direct contact between the official and the consumer of public services through the direct access to public services (direct access model);

- monitoring the financial activity of people potentially exposed to corruption, members of their families (financial monitoring model).

The public service transparency model has proven itself well at the launch of crowdsourcing platforms [8]. As an example, we can take the portal "I Paid A Bribe", which allows users to anonymously report facts of bribery in the government agencies (India), as well as the system "Check My School", which allows parents to control the costs of schools (Philippines).

The disadvantage of these platforms is the anonymity of users and the inability to identify them. With such options, it is difficult to verify data on corruption crimes. On the contrary, in the case of the identification of applicants, the effectiveness of the detection of corruption crimes increases by an average of $60 \%$.

The feedback model is implemented through the introduction of public information portals [8]. These portals are created by government agencies or non-governmental organizations in order to make the information about the work of 
government agencies publicly available (Argentine portal "Dinero y Politica", containing information about the finances of political parties in the country; OpenSpending.org, reflecting the movement of budget funds). The problem of the considered model is that the feedback sites are controlled by law enforcement agencies, which means that the completeness and quality of the posted information depends only on them.

The open document flow model based on Blockchain and Artificial Intelligence technologies has a great preventive potential. The use of new technologies in the traditional document management allows not only to ensure the movement of documents, but also to use the logistics and analytical resources of new networks.

In March 2019, at the OECD conference, a competition of scientific papers was held where it was found that Big Data and Artificial Intelligence technologies can help by detecting corruption [11, 12]. The model for the automated decision-making process is also gaining popularity. It involves the collection of legally significant information [13] and the adoption of legal decisions on this basis.

In the framework of the proposed model, an official as a subject of volitional decisions is excluded from traditional corruption schemes, and therefore there is no need to pay a bribe. In the framework of the proposed model, the decision to issue rare drugs on benefits will not be made by doctors potentially exposed to corruption offenses, but by a system based on data on age, health status, etc. In the optimal case, the entire procedure of decision-making and execution should be automated through the use of smart contracts. For example, entering data about the dismissal or death of a person into a single information system will entail the automatic termination of social and other payments in relation to him. But despite the obvious advantages of this model, there are a number of risks associated with the assessment of legal consequences of the automatically rendered decisions execution, in particular, the responsibility for wrongful decision or errors.

The direct access model assumes the exclusion of direct contact between the consumer of public services and the official making decisions, which significantly reduces corruption risks. The proposed model provides an opportunity for any user through his personal account to carry out online operations with documents in real time and track them $24 / 7$. Similar experience is already being implemented in Russia. With the approval of the digital program, public authorities were the first ones who began to move from paper to digital media.

In addition, specialized websites and applications have been created, for example, the public services portal, which has been operating since 2010 and has been used very successfully. In 2017, the number of registered users of the portal increased by 25 million and amounted to 65 million people, and the share of citizens using electronic public services increased from $25 \%$ in 2012 to just over $64 \%$ in 2017 [14].

Within the framework of combating corruption, the financial monitoring model has been used quite successfully, this model allows analyzing the financial activity of persons potentially exposed to corruption, members of their families, both during the period of their respective positions and within three years after their dismissal.

This system is based on a constantly updated database, which collects and primarily processes personal information about these people, primarily financial and property status, information about all banking operations, information about payment of fines, housing, loans, taxes and other payments. Each public authority within its jurisdiction defines the types of information that will be received for storage in the database.

The problem, however, is that the proposed model is poorly consistent with the modern system of collection and storage of personal information, and in some cases, it is in the open conflict with the rules on the personal life protection. In addition, the question of what liability will follow in the case of non-reporting or reporting false or incomplete information about the movement of tangible assets is also unresolved.

\section{Conclusion}

The introduction of digital technologies in the system of public administration and anti-corruption policy of companies allows achieving a significant reduction in the level of corruption by increasing the transparency of the process and ensuring contactless provision of public services. But these advantages of digital technologies are minimized by the lack of a universal electronic document management system, the lack of technical and legal criteria for the verification of revealed facts and the information security system. It is obvious that the important condition for the implementation of the above presented digital models is their consistency with the current criminal, administrative and information legislation, as well as with modern methods of combating cybercrimes.

\section{References}

1. E.L. Sidorenko, A.A. Lykov, Prospects for the legal regulation of Central Bank digital currency. In Ashmarina S., Vochozka M., Mantulenko V. (Eds.), Digital age: Chances, challenges and future. ISCDTE 2019. Lecture Notes in Networks and Systems, 84 (pp. 613-623). Cham: Springer (2020). DOI: 10.1007/978-3-030-27015-5_73.

2. S.V. Ivantsov, E.L. Sidorenko, B.A. Spasennikov, Yu.M. Berezkin, Ya.A. Sukhodolov, Cryptocurrency-related crimes: Key criminological trends. Russian Journal of Criminology, 13(1), 85-93 (2019). DOI: 10.17150/25004255.2019.13(1).85-93. [in Rus]. 
3. R. van Wegberg, J. Oerlemans, O. van Deventer, Bitcoin money laundering: Mixed results? An explorative study on money laundering of cybercrime proceeds using bitcoin. Journal of Financial Crime, 25(2), 419-435 (2018). DOI: 10.1108/JFC-11-2016-0067.

4. S. Kethineni, Y. Cao, C. Dodge, Use of bitcoin in Darknet markets: Examining facilitative factors on bitcoin-related crimes. American Journal of Criminal Justice, 43(2), 141-157 (2017). DOI: 10.1007/s12103-017-9394-6.

5. Basel Institute on Governance, New perspectives in e-government and the prevention of corruption. Working Paper 23 (2017). URL: https://www.baselgovernance.org/publications/working-paper-23-new-perspectives-e-governmentand-prevention-corruption. Accessed: 21.10.19.

6. United Nations Department of Economic and Social Affairs, United Nations e-government survey 2016: Egovernment in support of sustainable development (2016). URL: http://workspace.unpan.org/sites/Internet/Documents/UNPAN97453.pdf. Accessed: 01.10.19.

7. L. Ante, Cryptocurrency, blockchain and crime. In: K. McCarthy (Ed.) The money laundering market: Regulating the criminal economy (pp.171-198). Agenda Publishing, Newcastle upon Tyne (2018). DOI: 10.2307/j.ctv5cg8z1.10.

8. I. Adam, M. Fazekas, Are emerging technologies helping win the fight against corruption in developing countries? Pathways for Prosperity Commission. Background Paper Series; no. 21 (2018). URL: http://www.govtransparency.eu/wp-content/uploads/2019/02/ICT-corruption-24Feb19_FINAL.pdf. Accessed: 01.10 .19 .

9. R. Banning-Lover, Nine ways to use technology to reduce corruption. The Guardian, Thu 26 May 2016 17.16 BST. (2016). URL: https://www.theguardian.com/global-development-professionals-network/2016/may/26/nine-ways-touse-technology-to-reduce-corruption. Accessed: 01.10.19.

10. Regional School of Public Administration, Abuse of information technology (IT) for corruption (2013). URL: https://respaweb.eu/download/doc/Abuse+of+Information+Technology+\%28IT\%29+for+Corruption.pdf/d867df158 b864e8c843c15e5eece5016.pdf. Accessed: 01.10.19.

11. I. Fountoukidis, E. Dafli, Analyzing the corruption on a procurement network using Graph theory. OECD Global Anti-Corruption \& Integrity Forum, 2019. OECD Conference Centre, Paris (2019). URL: https://www.oecd.org/corruption/integrity-forum/academic-papers/Fountoukidis-Dafli-graph-theory.pdf. Accessed: 01.10 .19

12. R. Milani, The impact of corruption on procurement performance. An assessment of Italian public work contracts and suppliers. OECD Global Anti-Corruption \& Integrity Forum, 2019. OECD Conference Centre, Paris ( 2019). URL: $\quad$ https://www.oecd.org/corruption/integrity-forum/academic-papers/Milani\%202019\%20CorruptionProcurement\%20Youth\%20ResearchEdge\%20Papers.pdf. Accessed: 01.10.19.

13. V.M. Koryakin, "Digitalization" of public relations and its impact on the state of corruption in the military organization of the state. Obosnik (electronic journal) (2019). URL: http://www.oboznik.ru/?p=63821. Accessed: 01.10.19. [in Rus.].

14. A.K. Moiseevskaya, Implementation of anti-corruption policy in the conditions of digitalization of economy and society. Scientific Notes of Young Researchers, 3, 62-68 (2018). [in Rus.]. 